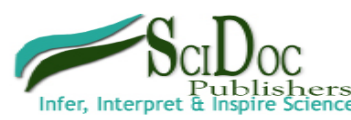

International Journal of Stem Cell Research and Transplantation (1JST)

ISSN: $2328-3548$

\title{
Differentiation of Neural Progenitor Cells from Pluripotent Stem Cells in Artificial Niches
}

Yan $\mathrm{Y}^{1}$, Sart $\mathrm{S}^{1}, \mathrm{Li} \mathrm{Y}^{1^{*}}$

Review Article

${ }^{1 *}$ Department of Chemical and Biomedical Engineering, FAMU-FSU College of Engineering, Florida State University, 2525 Pottsdamer St, Tallahassee, Florida, USA

\begin{abstract}
Neural progenitor cells (NPCs) derived from pluripotent stem cells (PSCs) provide a promising cell source for disease modeling, drug screening, and tissue engineering. To fulfill the potentials of PSC-derived NPCs, a series of fundamental issues, especially the effects of stem cell niches, need to be elucidated to gain a precise control over stem cell response. This article discussed several important niche factors that affect NPC differentiation from PSCs: 1) seeding density to represent cell-cell interactions; 2) the extracellular matrix (ECM)-bound growth factors to present cell-growth factor interactions; and 3) the substrate stiffness to represent cell-matrix interactions. Understanding the effects of these factors will better recreate the stem cell niche to promote neural differentiation from PSCs.
\end{abstract}

Key Words: Pluripotent Stem Cell; Extracellular Matrix; Neural Differentiation.

\author{
*Corresponding Author: \\ Yan Li, \\ Department of Chemical and Biomedical Engineering, FAMU-FSU Col- \\ lege of Engineering, Florida State \\ University, Tallahassee, Florida, USA \\ Tel: 850-410-6320; Fax: 850-410-6150 \\ E-mail: yli@eng.fsu.edu
}

Received: July 12, 2013

Accepted: July 24, 2013

Published: July 25, 2013

Citation: Yan Y, Sart S, Li Y. (2013). Differentiation of Neural Progenitor Cells from Pluripotent Stem Cells in Artificial Niches, Int J Stem Cell Res Transplant, 01(04), 22-27. doi: http://dx.doi.org/10.19070/2328$3548-130004$

Copyright: Li $\mathbf{Y}^{\odot}$ 2013. This is an open-access article distributed under the terms of the Creative Commons Attribution License, which permits unrestricted use, distribution and reproduction in any medium, provided the original author and source are credited.

\section{Introduction}

Recently pluripotent stem cells (PSCs), including embryonic stem cells (ESCs) and induced pluripotent stem cells (iPSCs), have emerged as promising cell sources for regenerative medicine and drug discovery towards the treatments of various incurable neural diseases or injuries [1-4]. In many cases, the pathological trauma or disorder of adult central nerve system (CNS) is unable to be healed and repaired [5-7]. For instance, when spinal cord is injured, the motor neurons may lose function permanently, due to the inability of the spinal myelin to regenerate [5]. This paralysis leads to the loss of sensation below the site of spinal injury, which causes paraplegia or quadriplegia of patients [6]. Neural progenitor cells (NPCs) derived from PSCs possess the great potential to develop restorative treatments for neurodegenerative diseases, such as stroke, traumatic brain injury, spinal cord injury, or other CNS disorders [8-10]. PSC-derived NPCs can be differentiated into primary CNS lineages including neurons, astrocytes, or oli- godendrocytes. As progenitors, these cells can also be cultivated for many passages without losing the differentiation capacity in vitro and easily be expanded in scalable process using bioreactors $[11,12]$.

To utilize PSC-derived NPCs successfully and effectively, a series of fundamental issues especially the effects of microenvironment need to be elucidated to gain a precise and predictable control over stem cell responses, in terms of self-renewal, migration, and differentiation. However, a better understanding of the interactions among stem cells, the specific microenvironment or "niche", and extrinsic signals or forces is currently uncertain and implicit [13]. Three-dimensional (3-D) scaffolds can provide physical support to create functional tissue and the cues to regulate PSC differentiation for clinical applications in regenerative medicine and tissue engineering $[14,15]$. The use of extracellular matrices (ECMs) derived from decellularized tissues or organs as 3-D scaffolds has drawn increasing attention due to its ability to provide in vivo-like stem cell niche [16-18]. One advantage of ECM-based scaffolds is the high biocompatibility due to the fact that scaffolds come from native tissues or cell cultures [19,20]. Besides the applications for in vivo transplantation, ECM scaffolds can also be used for in vitro cell expansion and differentiation [21]. The structure and properties of the decellularized matrix can well modulate or maintain the differentiated phenotype of the reseeded cells $[19,22]$.

Recent studies have shown that the biological scaffolds derived from PSC-secreted ECMs can serve as ideal and suitable microenvironment for tissue regeneration [23-25]. The decellularized PSC-derived ECMs have been shown to recapitulate the molecular and cellular milieu, mimic the 3-D microenvironment of embryonic development in vivo, and are used to obtain large-quantity and high-quality cells [26,27]. Hence, these ECMs become the promising scaffolds to provide the native niche for stem cell differentiation. However, the interactions of stem cells with the niche factors especially ECMs during stem cell growth and differentiation have not been fully characterized, due to the complex 3-D structural and functional cell organizations in the matrices 
$[17,28]$.

In this article, the important roles of several stem cell niche factors, including seeding density, the ECM-bound growth factors, and the substrate stiffness are discussed, based on PSC-derived ECM scaffolds for neural differentiation. In particular, how the proliferation and differentiation of NPCs are driven by biological components and mechanical cues of the matrices is reviewed. Specifically, the effects of the seeding density and the ECMbound growth factors on NPC proliferation and expansion are discussed. Because the decellulaized ECM scaffolds can be modified by crosslinking agents that affect the Young's modulus, the influence of scaffold modulus on neural differentiation is also summarized.

\section{Stem Cell Niche}

Stem cells are surrounded by specialized niches comprising of a variety of cell-specific cues. Although these cues are extremely complicated, they can be divided into three primary groups: cellcell interactions, cell-growth factor interactions, and cell-matrix interactions[29-31]. Previously, several reports demonstrated that well-modulated intrinsic and external signals such as soluble/ immobilized growth factors and cell-cell contacts influence and tune the proliferation and differentiation of NPCs [32-35]. The cell-cell interactions can be simply modulated by seeding density, which impacts the frequency of cell-cell contacts. For the cellgrowth factor interactions, the dynamic association of grow factors with ECMs is recently found to play an important role in affecting stem cell fate decision [36]. ECMs can serve as a reservoir of the growth factors, controlling their sequestration, release, and thus their biological activities [37]. The immobilized growth factors in ECMs have been found to be more potent than the soluble growth factors [38]. For cell-matrix interactions, the impacts of mechanical properties of the matrix, such as elastic modulus, on the differentiation profile of NPCs and neural differentiation of PSCs are also shown $[39,40]$. Stem cells cultured on hydrogels with varied stiffness demonstrated that substrate elastic modulus can alter critical cellular events, such as ECM assembly, cell motility, and cell spreading $[13,41,42]$. Although the physicochemical cues which NPCs require for self-renewal, migration and differentiation are starting to be understood [30], significant work still need to be done to elucidate the effects of stem cell niche factors on neural tissue development. So, 3-D tissue engineering scaffolds need to incorporate the cues of native stem cell niche in order to precisely guide stem cell fate decisions and cell functions, such as migration, proliferation, and differentiated phenotype $[17,43]$.

\section{Cell-Cell Interactions}

\section{Effect of Seeding Density}

The seeding density is a crucial parameter in regulating cell-cell interactions and neural tissue regeneration by controlling cell-cell contacts [30]. The cell-cell contacts maintained gap junctions and promoted the expression of adhesion molecules such as E-cadherin and N-cadhetin $[44,45]$. The cadherins of NPCs acted as anchoring points for the actin cytoskeleton organization and regulated cell proliferation and differentiation [46]. To obtain homogeneous ECM deposition in vitro, it is also necessary to acquire a large amount of cells uniformly distributed in the scaffolds. On the other hand, high seeding density could create the limitations in nutrient diffusion and transport, affecting cellular metabolism, cell viability, and differentiation potential [47] In a recent study, human stem cells were seeded on calcium phosphate cement at a density range of $5 \times 10^{4}$ to $3 \times 10^{5}$, cell viability and the differentiated function increased with seeding density [48]. The cell seeding density was also shown to impact contraction kinetics of stem cells on collagen constructs and induced the changes in cellular morphology [49]. These changes in cell nuclear morphology stimulated differentiation pathway of fibroblastic lineage, which implied that the seeding density could influence stem cell multi-

Figure 1: Neural differentiation from pluripotent stem cells (PSCs). (A) Neural marker expression in neural progenitors derived from PSCs: nestin (progenitor), $\beta$-tubulin III(neuron), musashi-1 (progenitor), and GFAP (astrocyte). Scale bar: $100 \mu \mathrm{m}$. (B) and (C) indicated the role of retinoic acid (RA)-RA receptor (RAR) interactions in ESCs cultured on the decellularized extracellular matrix (ECM) scaffolds (adapted from Sart et al [27]). (B) Localization of RAR- $\alpha$ in ESC monolayers. In the absence of RA, RAR- $\alpha$ localized in cytoplasm. With RA treatment, RAR- $\alpha$ expression was observed in nucleus (Scale bar: 50 $\mu \mathrm{m})$. (C) Confocal images of RAR- $\alpha$ in reseeded ESCs on the ECM scaffolds derived from RA-treated embryoid bodies (Scale bar: $100 \mu \mathrm{m})$. RAR- $\alpha$ was observed both in cytoplasm and nucleus even in the absence of RA, indicating the signaling effect of ECM scaffolds. Green arrow: RAR- $\alpha$ expression in cell nucleus; white arrow: RAR- $\alpha$ expression in cytoplasm.

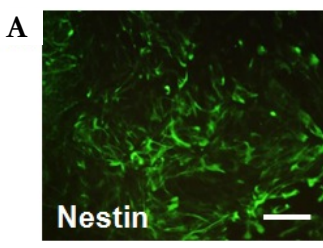

B ESC Monolayer

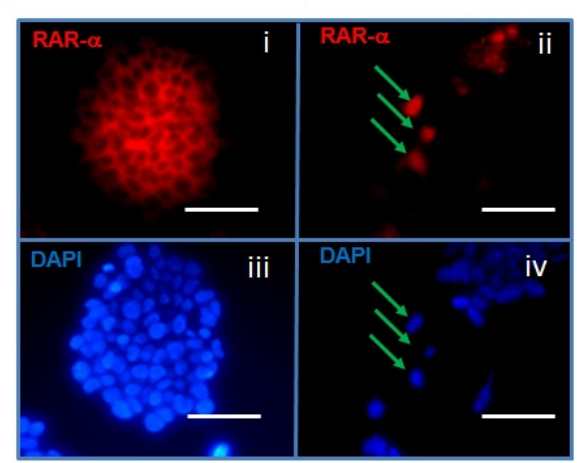

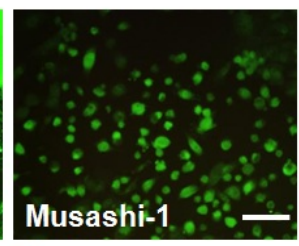

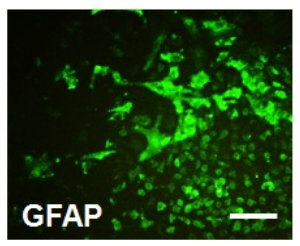

C

ESC on ECM Scaffold

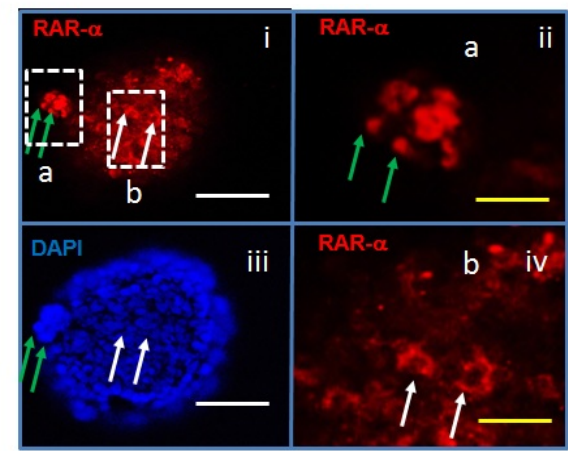


potential differentiation.

Seeding density has been shown to modulate the effects of Rho Kinases in regulation of ESC self-renewal and neural differentiation [50]. While at low seeding density $(2 \times 103$ cells $/ \mathrm{cm} 2)$, treatment with Rho-associated protein kinase (ROCK) inhibitor Y27632 did not affect ESC self-renewal, at high seeding density $(1 \times 104$ cells $/ \mathrm{cm} 2)$ Y27632-treated cells expressed the reduced level of Oct-4 and predominantly differentiated into neural lineage. These results suggested that the ROCK signaling may be activated by cell-cell contacts at high density and ROCK inhibition dys-regulated $\beta$-catenin localization induced by cell-cell contacts, affecting the lineage commitment [50]. The seeding density also played an important role in embryoid body (EB) formation during neural differentiation [51]. The high density-EBs were found to result in neuron subtype along anterior-posterior axis while low density-EBs induced the differentiation into a more caudalized subtype. Our lab has derived NPCs from ESCs expressing nestin and Musashi-1 using EB-based protocol at high seeding density (Figure 1). The replated NPCs readily differentiated into neurons $(\beta$-tubulin III + cells) and astrocytes (GFAP+ cells).

Cell seeding density also affected the 3-D aggregate size for PSC expansion and $\mathrm{EB}$ formation. The defined numbers of human PSCs were seeded into 96-, 386-, or AggreWell plates and aggregates with a series of defined size can be formed [52]. Different aggregate size has been shown to affect lineage specific differentiation. For example, the small EBs $(\sim 77 \mu \mathrm{m})$ enriched endoderm cells, the large EBs $(\sim 334 \mu \mathrm{m})$ promoted ectoderm differentiation, and the intermediate EBs $(\sim 210 \mu \mathrm{m})$ were better for mesoderm induction [53]. In 3-D ECM scaffolds, applying novel seeding methods to optimize seeding density has been a critical step to regulatecell organization and functional differentiation [26].

\section{Cell-Growth Factor Interactions}

\section{Effect of the ECM-Bound Growth Factors}

Growth factors can be sequestered in the ECMs such as proteoglycans and presented to the receptors on cell surface, constituting the dynamic interactions of growth factor and ligand binding [37]. In addition, ECMs serve as the reservoir of growth factors, organize the cytokine gradients, and mediate the release of growth factors in the presence of mechanical force or during ECM remodeling [13]. Compared to soluble growth factors, the bound growth factors tethered with ECM components have increased protein stability and provide persistent signaling [38]. For example, fibroblast growth factor (FGF)-2 covalently attached to the synthetic polymer showed 100-fold higher potency compared to FGF-2 in solution [54]. Therefore, the function of receptors on cell membrane is contingent on the mode of growth factor presentation.

FGF-2 is an important regulator during human PSC self-renewal and neural differentiation [55,56]. FGF-2 is known to bind heparin sulfate proteoglycans and influence cell fate through the activation of mitogen-activated protein kinase (MAPK) and the phosphorylation of extracellular signal-regulated protein kinases (ERK) [57]. FGF-2 has a wide range of biological functions and effects on cell survival, self-renewal, and differentiation. Especially, FGF-2 has the potential of neuronal-induction and the cells from non-neuronal origin can be differentiated into neuronal phenotypes when treated by FGF-2 [58]. In a recent study, mouse ESCs induced by FGF-2 generated neuronal tube in vitro, show- ing the effect of FGF-2 on ESC growth and differentiation [59]. Since FGF-2 is an important modulator responsible for PSC proliferation and neural differentiation, the impact of matrix-bound FGF-2 should be considered for NPC behavior in ECM scaffolds.

Besides FGF-2, other growth factors have also demonstrated the effects on neural cell proliferation and differentiation. Small molecules such as retinoic acid (RA), as well as growth factors such as transforming growth factor (TGF)- $\beta 1$, brain-derived neurotrophic factor (BDNF), and nerve growth factor (NGF), etc., have been shown to affect neural differentiation [2,60-62]. For example, TGF- $\beta 1$ is associated with matrix proteins such as fibronectin, fibrillin, and proteoglycans [63]. Its sequestration and release from ECMs is an important mechanism that regulates its bioactivity [63,64]. TGF- $\beta 1$ has been shown to exert anti-apoptotic and growth and migration-enhancing activities on NPCs through SMAD2 (for growth and migration) or ERK1/2 (for anti-apoptotic behavior) signaling [65]. The interactions of these growth factors with ECMs potentiate their effects on stem cell fate decision.

Although the roles of specific growth factors and signaling pathways on NPC differentiation and function have been discussed previously in monolayer culture [66], their influence in 3-D culture and the interactions with ECMs have not been fully studied. In particular, 3-D decellularized PSC-derived ECM scaffolds have been shown to preserve the signaling capacity during tissue development which is related to lineage specifications [26,27]. Our study has shown that retinoid signaling was present in the cells grown in ECM scaffolds derived from RA-treated EBs (Figure $1 \mathrm{~B}$ and 1C)[27]. The ESCs grown in this type of ECM scaffolds showed the decreased proliferation and Oct-4 expression and the increased neural marker expression compared to cells grown in ECM scaffolds derived from spontaneous EBs. The interactions of PSC-derived ECMs with other growth factors, especially the paracrine/autocrine factors, need to be fully understood $[25,67]$.

\section{Cell-Matrix Interactions: Effect of Matrix Stiff- ness}

\section{Matrix stiffness regulated stem cell fate decision}

PSCs and NPCs are sensitive to the biomechanical properties of the surrounding ECM microenvironment [68]. The mechanical cues or signals, including substrate stiffness, surface nanotopography, and extracellular forces can strongly guide stem cell fate decision [42,69]. Matrix stiffness, indicated by elastic modulus, has recently been demonstrated to be a critical biophysical factor that has significant effects on PSC self-renewal and neural differentiation (Table 1)[40,70,71]. Normally, cells sense elasticity during the attachment on the substrate through focal adhesions and formation of stress fibers. In most cases, their responses to the matrix properties relied on myosin-directed contraction and cell-ECM adhesions, which involve integrins, cadherins, and other adhesion molecules [72].

Pelham and Wang were the first group to modulate the elasticity of matrix by growing cells on collagen-coated polyacrylamide gel substrate [73]. Since then, the influences of substrate stiffness on regulating stem cell activities and directing stem cell fate have gained increasing interests [74]. Soft matrices have been shown to induceneuronal phenotypes in mesenchynal stem cells; stiffer substrates with modulus in the range of muscle tissue generated myogenic commitment, while rigid matrices mimicking collagen- 
ous bone favored osteogenic lineage [13,42]. The mechanical response of ESCs to the matrix stiffness was also observed recently. The spreading and proliferation of ESCs increased as the function of substrate stiffness [39]. And the softer substrate( $0.6 \mathrm{kPa}$ ) was shown to keep the self-renewal capability of mouse ESCs in the absence of leukemia inhibitory factor [75]. Human PSCs, however, preferred a stiff hydrogel $(\sim 10 \mathrm{kPa})$ which maintained cell proliferation and pluripotency via activation of paralogous proteins YAP/TAZ [72].

\section{Matrix stiffness regulated neural differentiation}

For NPCs, the influence and repercussions of substrate modulus seem to be more distinct and significant compared to other lineages. Native brain tissue is one of the softest tissues in the body (i.e. elastic modulus $(\mathrm{E})=0.5-1 \mathrm{kPa})[77,78]$ compared to other tissues or organs, such as muscle $(\mathrm{E} \sim 10 \mathrm{kPa})[79]$, cartilage tissue $(\mathrm{E} \sim 500 \mathrm{kPa})[80]$, connective tissue $(\mathrm{E} \sim 10 \mathrm{kPa})$, and cortical bone $(\mathrm{E} \sim 107 \mathrm{kPa})$ [81]. In addition, the different parts of brain, including white and gray matter, pia mater, layered cell structures, glial scars and blood vessels, have a mechanical modulus varying from 0.5 to $50 \mathrm{kPa}[78,82]$. Thus, NPCs may encounter different biomechanical environments and biomechanical cues, in particular stiffness of substrate, which play important roles in NPC differentiation [77].

Several groups have shown that neurons, glia and neural differentiation were promoted on soft substrates while rigid matrix was preferable for mesoderm cells $[83,84]$. Saha et al developed a synthetic hydrogel to evaluate the effects of substrate modulus on hippocampus-derived NPC differentiation [77]. Soft gels (E 100-500 Pa) were found to favor neurons while harder gels $(\mathrm{E} \sim 1,000-10,000 \mathrm{~Pa}$ ) promoted the NPC differentiation into glial cells. The study by Leipzig et al also precisely controlled neural stem cell proliferation and differentiation by optimizing hydrogel elasticity [32]. The stiff ness of the photocrosslinkable hydrogel scaffolds was modulated by varying the concentration of a photointiator, 2, 2-dimethoxy-2-phenylacetophenone (DMAP) [32]. The results showed that NPCs preferably differentiated into neurons on very soft substrates $(\mathrm{E}<1 \mathrm{kPa})$, astrocytes on stiffer ones $(\mathrm{E} \sim 1-3.5 \mathrm{kPa})$, and oligodendrocytes on the stiffest substrate $(\mathrm{E}$ $>7 \mathrm{kPa}$ ). However, the differences in oligodendrocyte maturation may exist on different substrates, as myelination tests showed maturation and myelination was the best at modulus $<1 \mathrm{kPa}[32]$.
Neural differentiation from human PSCs has also been found to be affected by modulus very recently $[40,84]$. PSC differentiation into each germ layer was affected by different stiffness of the scaffolds. Neural differentiation (ectoderm) was found to be promoted by soft ECMs $(<0.1 \mathrm{MPa})$, while intermediate ECMs $(0.1-1 \mathrm{MPa})$ were better for endoderm differentiation and stiff ECMs (1.5-6 MPa) promoted cardiomyocye differentiation (mesoderm) $[40,70,83,84]$. The soft ECM may result in less cell spreading, higher cell packing density, and more condensed cell/nuclear shape, which played import roles during neurogenesis [40]. In contrast, mesoderm differentiation may require higher intercellular force which was enhanced on stiff matrix [84]. Compared to the alteration of lineage commitment in adult NPCs, soft ECMs increased the population of early neural progenitors from human PSCs, reflecting the effect of matrix stiffness on the early embryonic development.

Combination of biological cue and stiffness of ECM scaffolds

To incorporate both biological factors with biomechanical signals, decellularized ECM scaffolds which recapitulate the cellular and molecular milieu of the cellular microenvironment, can be used to mimic the 3-D microenvironment of stem cells in vivo [27]. Although photo crosslinkable hydrogel provided a system where biomechanical cues could be incorporated in 3-D scaffolds [32], it lacked the biological molecules existing in the native 3-D tissues. Thus, scaffolds based on PSC-derived ECMs, which could contain biological cues corresponding to the development stage, need to be designed and developed. Here, by varying the concentration of crosslinking agent genipin to treat ECM scaffolds, the effects of scaffold elastic modulus on the self-renewal and differentiation of PSC-derived NPCs can be examined (Figure 2) $[85,86]$. Our lab has used genipin to cross-link PSC-derived ECM scaffolds which increased the matrix modulus (unpublished data). The increased modulus affected neural differentiation of PSC-derived NPCs with higher modulus better maintaining the cells at progenitor stage. Thus, the cross-linking can be applied to tune the elasticity of ECM-based scaffolds to modulate neural differentiation. In this way, ECM scaffolds can provide biological factors in combination with biomechanical signals. Forming a hybrid of cell-derived ECM and synthetic ECM is also possible to provide aspectrum of biological and biomechanical signals in artificial niches and regulate stem cell fate [21].

Figure 2: The physical properties of extracellular matrix (ECM) scaffolds.(A) Ultrastructure of ECM scaffoldsderived from pluripotent stem cells assessed by scanning electron microscopy (SEM). (B) Representative images of surface roughness $(\sim 313 \mathrm{~nm})$, and $(C)$ modulus $(\sim 4 \mathrm{MPa})$ of ECM scaffolds analyzed by atomic force microscopy (AFM).
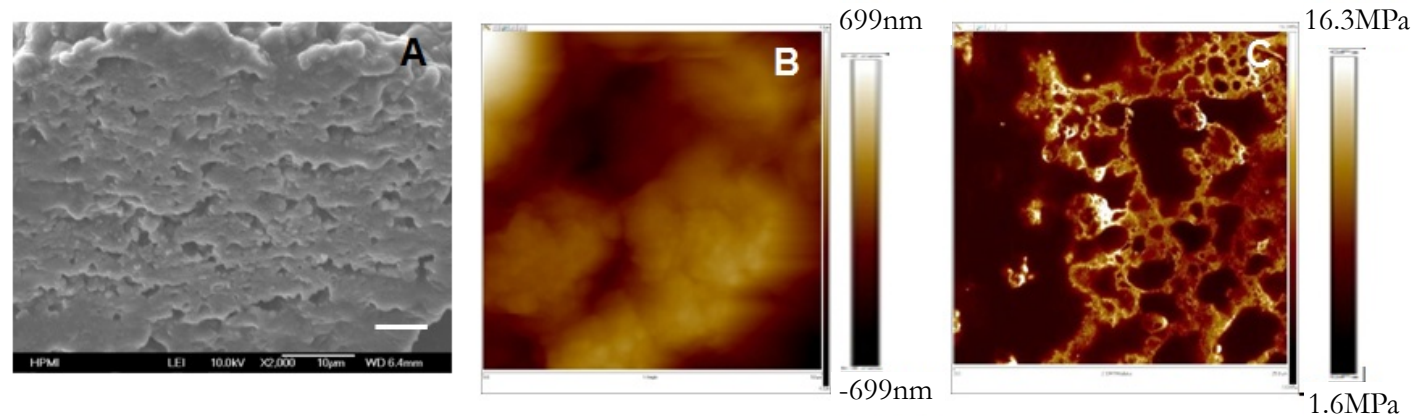


\section{Conclusion}

Recreating stem cell niches is critical for efficient derivation of NPCs from PSCs. The effects of several niche factors on neural differentiation were discussed here: seeding density to reflect cell-cell interactions; the ECM-bound growth factors to reflect cell-growth factor interactions; and matrix stiffness to reflect cellmatrix interactions. All these factors constitute the dynamic interactions influencing neural differentiation of PSCs. Differentiation of PSCs is regulated by physical and biochemical cues involving the immensely complex surrounding microenvironment. These environmental factors can be evaluated simply and individually in 2-D culture systems. However, the true and native 3-D composition of stem cell niches seems to be rarely estimable, due to the intrinsic complexity of the milieu combined with signals that cause synergistic effects on cell differentiation and function. Further studies on cell-cell or cell-ECM interactions occurring in ECM scaffolds need to be performed to elucidate the complex interactions in stem cell niche.

\section{Acknowledgements}

This work is supported by FSU Research Foundation GAP award. No conflict of interest is declared.

\section{References}

[1]. S.M. Chambers, C.A. Fasano, E.P. Papapetrou, M. Tomishima, M. Sadelain, L. Studer, Highly efficient neural conversion of human ES and iPS cells by dual inhibition of SMAD signaling, Nat Biotechnol, 27 (2009) 275-280.

[2]. D.S. Kim, J.S. Lee, J.W. Leem, Y.J. Huh, J.Y. Kim, H.S. Kim, I.H. Park, G.Q. Daley, D.Y. Hwang, D.W. Kim, Robust enhancement of neural differentiation from human ES and iPS cells regardless of their innate difference in differentiation propensity, Stem Cell Rev, 6 (2010) 270-281.

[3]. Y. Li, A. Gautam, J. Yang, L. Qiu, Z. Melkoumian, J. Weber, L. Telukuntla, R. Srivastava, E.M. Whiteley, R. Brandenberger, Differentiation of oligodendrocyte progenitor cells from human embryonic stem cells on vitronectin-derived synthetic peptide acrylate surface, Stem Cells Dev, 22 (2013) 1497-1505.

[4]. C. Xu, Differentiation and enrichment of cardiomyocytes from human pluripotent stem cells, J Mol Cell Cardiol, 52 (2012) 1203-1212.

[5]. V.M. Tysseling-Mattiace, V. Sahni, K.L. Niece, D. Birch, C. Czeisler, M.G. Fehlings, S.I. Stupp, J.A. Kessler, Self-assembling nanofibers inhibit glial scar formation and promote axon elongation after spinal cord injury, $\mathrm{J}$ Neurosci, 28 (2008) 3814-3823.

[6]. S. Thuret, L.D. Moon, F.H. Gage, Therapeutic interventions after spinal cord injury, Nat Rev Neurosci, 7 (2006) 628-643.

[7]. F. Yang, R. Murugan, S. Ramakrishna, X. Wang, Y.X. Ma, S. Wang, Fabrication of nano-structured porous PLLA scaffold intended for nerve tissue engineering, Biomaterials, 25 (2004) 1891-1900.

[8]. X.Y. Xu, X.T. Li, S.W. Peng, J.F. Xiao, C. Liu, G. Fang, K.C. Chen, G.Q. Chen, The behaviour of neural stem cells on polyhydroxyalkanoate nanofiber scaffolds, Biomaterials, 31 (2010) 3967-3975.

[9]. K.S. Straley, C.W. Foo, S.C. Heilshorn, Biomaterial design strategies for the treatment of spinal cord injuries, J Neurotrauma, 27 (2010) 1-19.

[10]. P.A. Walker, K.R. Aroom, F. Jimenez, S.K. Shah, M.T. Harting, B.S. Gill, C.S. Cox, Jr., Advances in progenitor cell therapy using scaffolding constructs for central nervous system injury, Stem Cell Rev, 5 (2009) 283-300.

[11]. N. Liu, R. Zang, S.T. Yang, Y. Li, Stem cell engineering in bioreactors for large scale bioprocessing, Engineering in Life Sceinces, In press (2013).

[12]. M. McLeod, M. Hong, A. Sen, D. Sadi, R. Ulalia, L.A. Behie, I. Mendez, Transplantation of bioreactor-produced neural stem cells into the rodent brain, Cell Transplant, 15 (2006) 689-697.

[13]. D.E. Discher, D.J. Mooney, P.W. Zandstra, Growth factors, matrices, and forces combine and control stem cells, Science, 324 (2009) 1673-1677.

[14]. T.P. Kraehenbuehl, R. Langer, L.S. Ferreira, Three-dimensional biomaterials for the study of human pluripotent stem cells, Nat Methods, 8 (2011) 731-736.

[15]. N. Liu, A. Ouyang, Y. Li, S.T. Yang, Three-dimensional neural differentiation of embryonic stem cells with ACM induction in microfibrous matrices in bioreactors, Biotechnol Prog, In Press (2013).

[16]. S.F. Badylak, D. Taylor, K. Uygun, Whole-organ tissue engineering: decel- lularization and recellularization of three-dimensional matrix scaffolds, Annu Rev Biomed Eng, 13 (2011) 27-53.

[17]. S.F. Badylak, The extracellular matrix as a biologic scaffold material, Biomaterials, 28 (2007) 3587-3593.

[18]. S.J. Hollister, Porous scaffold design for tissue engineering, Nat Mater, 4 (2005) 518-524

[19]. H. Lu, T. Hoshiba, N. Kawazoe, I. Koda, M. Song, G. Chen, Cultured cell-derived extracellular matrix scaffolds for tissue engineering, Biomaterials, 32 (2011) 9658-9666.

[20]. H. Lu, T. Hoshiba, N. Kawazoe, G. Chen, Autologous extracellular matrix scaffolds for tissue engineering, Biomaterials, 32 (2011) 2489-2499.

[21]. F.Z. Volpato, T. Fuhrmann, C. Migliaresi, D.W. Hutmacher, P.D. Dalton, Using extracellular matrix for regenerative medicine in the spinal cord, Biomaterials, 34 (2013) 4945-4955.

[22]. S.F. Badylak, D.O. Freytes, T.W. Gilbert, Extracellular matrix as a biological scaffold material: Structure and function, Acta Biomater, 5 (2009) 1-13.

[23]. R. Nair, S. Shukla, T.C. McDevitt, Acellular matrices derived from differentiating embryonic stem cells, J Biomed Mater Res A, 87 (2008) $1075-1085$.

[24]. A.V. Ngangan, T.C. McDevitt, Acellularization of embryoid bodies via physical disruption methods, Biomaterials, 30 (2009) 1143-1149.

[25]. R. Nair, A.V. Ngangan, M.L. Kemp, T.C. McDevitt, Gene expression signatures of extracellular matrix and growth factors during embryonic stem cell differentiation, PLoS One, 7 (2012) e 42580.

[26]. S.K. Goh, P. Olsen, I. Banerjee, Extracellular matrix aggregates from differentiating embryoid bodies as a scaffold to support ESC proliferation and differentiation, PLoS One, 8 (2013) e61856.

[27]. S. Sart, T. Ma, Y. Li, Extracellular matrices decellularized from embryonic stem cells maintained their structure and signaling specificity, Tissue Eng Part A In Press (2013).

[28]. W. Ma, T. Tavakoli, E. Derby, Y. Serebryakova, M.S. Rao, M.P. Mattson, Cell-extracellular matrix interactions regulate neural differentiation of human embryonic stem cells, BMC Dev Biol, 8 (2008) 90.

[29]. G. Vunjak-Novakovic, D.T. Scadden, Biomimetic platforms for human stem cell research, Cell Stem Cell, 8 (2011) 252-261.

[30]. V. Solozobova, N. Wyvekens, J. Pruszak, Lessons from the embryonic neural stem cell niche for neural lineage differentiation of pluripotent stem cells, Stem Cell Rev, 8 (2012) 813-829.

[31]. M. Liu, N. Liu, R. Zang, Y. Li, S.T. Yang, Engineering stem cell niches in bioreactors, World J Stem Cells, In press (2013).

[32]. N.D. Leipzig, M.S. Shoichet, The effect of substrate stiffness on adult neural stem cell behavior, Biomaterials, 30 (2009) 6867-6878.

[33]. C.H. Hung, T.H. Young, Differences in the effect on neural stem cells of fetal bovine serum in substrate-coated and soluble form, Biomaterials, 27 (2006) 5901-5908.

[34]. E. Cattaneo, R. McKay, Proliferation and differentiation of neuronal stem cells regulated by nerve growth factor, Nature, 347 (1990) 762-765.

[35]. K.K. Johe, T.G. Hazel, T. Muller, M.M. Dugich-Djordjevic, R.D. McKay, Single factors direct the differentiation of stem cells from the fetal and adult central nervous system, Genes Dev, 10 (1996) 3129-3140.

[36]. R.O. Hynes, The extracellular matrix: not just pretty fibrils, Science, 326 (2009) 1216-1219.

[37]. T. Rozario, D.W. DeSimone, The extracellular matrix in development and morphogenesis: a dynamic view, Dev Biol, 341 (2010) 126-140.

[38]. M.P. Lutolf, P.M. Gilbert, H.M. Blau, Designing materials to direct stemcell fate, Nature, 462 (2009) 433-441.

[39]. N.D. Evans, C. Minelli, E. Gentleman, V. LaPointe, S.N. Patankar, M. Kallivretaki, X. Chen, C.J. Roberts, M.M. Stevens, Substrate stiffness affects early differentiation events in embryonic stem cells, Eur Cell Mater, 18 (2009) 1-13; discussion 13-14.

[40]. A.J. Keung, P. Asuri, S. Kumar, D.V. Schaffer, Soft microenvironments promote the early neurogenic differentiation but not self-renewal of human pluripotent stem cells, Integr Biol (Camb), 4 (2012) 1049-1058.

[41]. A. Engler, L. Bacakova, C. Newman, A. Hategan, M. Griffin, D. Discher, Substrate compliance versus ligand density in cell on gel responses, Biophys J, 86 (2004) 617-628.

[42]. A.J. Engler, S. Sen, H.L. Sweeney, D.E. Discher, Matrix elasticity directs stem cell lineage specification, Cell, 126 (2006) 677-689.

[43]. C.J. Medberry, P.M. Crapo, B.F. Siu, C.A. Carruthers, M.T. Wolf, S.P. Nagarkar, V. Agrawal, K.E. Jones, J. Kelly, S.A. Johnson, S.S. Velankar, S.C. Watkins, M. Modo, S.F. Badylak, Hydrogels derived from central nervous system extracellular matrix, Biomaterials, 34 (2013) 1033-1040.

[44]. A. Cheng, H. Tang, J. Cai, M. Zhu, X. Zhang, M. Rao, M.P. Mattson, Gap junctional communication is required to maintain mouse cortical neural progenitor cells in a proliferative state, Dev Biol, 272 (2004) 203-216.

[45]. L. Li, B.H. Wang, S. Wang, L. Moalim-Nour, K. Mohib, D. Lohnes, L. Wang, Individual cell movement, asymmetric colony expansion, rho-associated kinase, and E-cadherin impact the clonogenicity of human embryonic stem cells, Biophys J, 98 (2010) 2442-2451.

[46]. S.R. Noles, A. Chenn, Cadherin inhibition of beta-catenin signaling regu- 
lates the proliferation and differentiation of neural precursor cells, Mol Cell Neurosci, 35 (2007) 549-558.

[47]. M.A. Kinney, C.Y. Sargent, T.C. McDevitt, The multiparametric effects of hydrodynamic environments on stem cell culture, Tissue Eng Part B Rev, 17 (2011) 249-262.

[48]. H. Zhou, M.D. Weir, H.H. Xu, Effect of cell seeding density on proliferation and osteodifferentiation of umbilical cord stem cells on calcium phosphate cement-fiber scaffold, Tissue Eng Part A, 17 (2011) 2603-2613.

[49]. H.A. Awad, D.L. Butler, M.T. Harris, R.E. Ibrahim, Y. Wu, R.G. Young, S. Kadiyala, G.P. Boivin, In vitro characterization of mesenchymal stem cellseeded collagen scaffolds for tendon repair: effects of initial seeding density on contraction kinetics, J Biomed Mater Res, 51 (2000) 233-240.

[50]. T.C. Chang, Y.C. Chen, M.H. Yang, C.H. Chen, E.W. Hsing, B.S. Ko, J.Y. Liou, K.K. Wu, Rho kinases regulate the renewal and neural differentiation of embryonic stem cells in a cell plating density-dependent manner, PLoS One, 5 (2010) e9187.

[51]. J.M. Zhou, F.Y. Xing, J.J. Shi, Z.F. Fang, X.J. Chen, F. Chen, Quality of embryonic bodies and seeding density effects on neural differentiation of mouse embryonic stem cells, Cell Biol Int, 32 (2008) 1169-1175.

[52]. M.D. Ungrin, C. Joshi, A. Nica, C. Bauwens, P.W. Zandstra, Reproducible, ultra high-throughput formation of multicellular organization from single cell suspension-derived human embryonic stem cell aggregates, PLoS One, 3 (2008) e1565.

[53]. C.L. Bauwens, R. Peerani, S. Niebruegge, K.A. Woodhouse, E. Kumacheva, M. Husain, P.W. Zandstra, Control of human embryonic stem cell colony and aggregate size heterogeneity influences differentiation trajectories, STEM CELLS, 26 (2008) 2300-2310.

[54]. E.K.A. Nur, I. Ahmed, J. Kamal, A.N. Babu, M. Schindler, S. Meiners, Covalently attached FGF-2 to three-dimensional polyamide nanofibrillar surfaces demonstrates enhanced biological stability and activity, Mol Cell Biochem, 309 (2008) 157-166.

[55]. L.M. Przybyla, J. Voldman, Attenuation of extrinsic signaling reveals the importance of matrix remodeling on maintenance of embryonic stem cell self-renewal, Proc Natl Acad Sci U S A, 109 (2012) 835-840.

[56]. G. Nistor, M.M. Siegenthaler, S.N. Poirier, S. Rossi, A.J. Poole, M.E. Charlton, J.D. McNeish, C.N. Airriess, H.S. Keirstead, Derivation of high purity neuronal progenitors from human embryonic stem cells, PLoS One, 6 (2011) e20692.

[57]. J. Kim, T. Ma, Autocrine fibroblast growth factor 2-mediated interactions between human mesenchymal stem cells and the extracellular matrix under varying oxygen tension, J Cell Biochem, 114 (2013) 716-727.

[58]. H. Yang, Y. Xia, S.Q. Lu, T.W. Soong, Z.W. Feng, Basic fibroblast growth factor-induced neuronal differentiation of mouse bone marrow stromal cells requires FGFR-1, MAPK/ERK, and transcription factor AP-1, J Biol Chem, 283 (2008) 5287-5295

[59]. S. Chiba, M.S. Kurokawa, H. Yoshikawa, R. Ikeda, M. Takeno, M. Tadokoro, H. Sekino, T. Hashimoto, N. Suzuki, Noggin and basic FGF were implicated in forebrain fate and caudal fate, respectively, of the neural tube-like structures emerging in mouse ES cell culture, Exp Brain Res, 163 (2005) 86-99.

[60]. M. Schuldiner, O. Yanuka, J. Itskovitz-Eldor, D.A. Melton, N. Benvenisty, Effects of eight growth factors on the differentiation of cells derived from human embryonic stem cells, Proc Natl Acad Sci U S A, 97 (2000) $11307-$ 11312.

[61]. H. Lee, G.A. Shamy, Y. Elkabetz, C.M. Schofield, N.L. Harrsion, G. Panagiotakos, N.D. Socci, V. Tabar, L. Studer, Directed differentiation and transplantation of human embryonic stem cell-derived motoneurons, STEM CELLS, 25 (2007) 1931-1939.

[62]. Y. Okada, T. Shimazaki, G. Sobue, H. Okano, Retinoic-acid-concentration-dependent acquisition of neural cell identity during In vitro differentiation of mouse embryonic stem cells, Dev Biol, 275 (2004) 124-142.

[63]. R.G. Wells, D.E. Discher, Matrix elasticity, cytoskeletal tension, and TGFbeta: the insoluble and soluble meet, Sci Signal, 1 (2008) pe13.

[64]. Q. Chen, P. Sivakumar, C. Barley, D.M. Peters, R.R. Gomes, M.C. FarachCarson, S.L. Dallas, Potential role for heparan sulfate proteoglycans in regulation of transforming growth factor-beta (TGF-beta) by modulating assembly of latent TGF-beta-binding protein-1, J Biol Chem, 282 (2007) 26418-26430.
[65]. S.M. Park, J.S. Jung, M.S. Jang, K.S. Kang, S.K. Kang, Transforming growth factor-beta1 regulates the fate of cultured spinal cord-derived neural progenitor cells, Cell Prolif, 41 (2008) 248-264.

[66]. A.M. Bratt-Leal, R.L. Carpenedo, T.C. McDevitt, Engineering the embryoid body microenvironment to direct embryonic stem cell differentiation, Biotechnol Prog, 25 (2009) 43-51.

[67]. C. Hughes, L. Radan, W.Y. Chang, W.L. Stanford, D.H. Betts, L.M. Postovit, G.A. Lajoie, Mass spectrometry-based proteomics analysis of the matrix microenvironment in pluripotent stem cell culture, Mol Cell Proteomics, 12 (2012) 1924-1936.

[68]. J.K. Earls, S. Jin, K. Ye, Mechanobiology of Human Pluripotent Stem Cells, Tissue Eng Part B Rev, (2013).

[69]. M.M. Nava, M.T. Raimondi, R. Pietrabissa, Controlling self-renewal and differentiation of stem cells via mechanical cues, J Biomed Biotechnol, 2012 (2012) 797410.

[70]. N. Eroshenko, R. Ramachandran, V.K. Yadavalli, R.R. Rao, Effect of substrate stiffness on early human embryonic stem cell differentiation, J Biol Eng, 7 (2013) 7.

[71]. Y. Sun, L.G. Villa-Diaz, R.H. Lam, W. Chen, P.H. Krebsbach, J. Fu, Mechanics regulates fate decisions of human embryonic stem cells, PLoS One, 7 (2012) e37178.

[72]. D.E. Discher, P. Janmey, Y.L. Wang, Tissue cells feel and respond to the stiffness of their substrate, Science, 310 (2005) 1139-1143.

[73]. R.J. Pelham, Jr., Y. Wang, Cell locomotion and focal adhesions are regulated by substrate flexibility, Proc Natl Acad Sci U S A, 94 (1997) 13661-13665.

[74]. S. Nemir, J.L. West, Synthetic materials in the study of cell response to substrate rigidity, Ann Biomed Eng, 38 (2010) 2-20.

[75]. F. Chowdhury, Y. Li, Y.C. Poh, T. Yokohama-Tamaki, N. Wang, T.S. Tanaka, Soft substrates promote homogeneous self-renewal of embryonic stem cells via downregulating cell-matrix tractions, PLoS One, 5 (2010) e15655.

[76]. S. Musah, S.A. Morin, P.J. Wrighton, D.B. Zwick, S. Jin, L.L. Kiessling, Glycosaminoglycan-binding hydrogels enable mechanical control of human pluripotent stem cell self-renewal, ACS Nano, 6 (2012) 10168-10177.

[77]. K. Saha, A.J. Keung, E.F. Irwin, Y. Li, L. Little, D.V. Schaffer, K.E. Healy, Substrate modulus directs neural stem cell behavior, Biophys J, 95 (2008) 4426-4438.

[78]. Z. Taylor, K. Miller, Reassessment of brain elasticity for analysis of biomechanisms of hydrocephalus, J Biomech, 37 (2004) 1263-1269.

[79]. A.M. Collinsworth, S. Zhang, W.E. Kraus, G.A. Truskey, Apparent elastic modulus and hysteresis of skeletal muscle cells throughout differentiation, Am J Physiol Cell Physiol, 283 (2002) C1219-1227.

[80]. K.A. Athanasiou, M.P. Rosenwasser, J.A. Buckwalter, T.I. Malinin, V.C. Mow, Interspecies comparisons of in situ intrinsic mechanical properties of distal femoral cartilage, J Orthop Res, 9 (1991) 330-340.

[81]. F. Katsamanis, D.D. Raftopoulos, Determination of mechanical properties of human femoral cortical bone by the Hopkinson bar stress technique, J Biomech, 23 (1990) 1173-1184.

[82]. Y.B. Lu, K. Franze, G. Seifert, C. Steinhauser, F. Kirchhoff, H. Wolburg, J. Guck, P. Janmey, E.Q. Wei, J. Kas, A. Reichenbach, Viscoelastic properties of individual glial cells and neurons in the CNS, Proc Natl Acad Sci U S A, 103 (2006) 17759-17764.

[83]. A. Arshi, Y. Nakashima, H. Nakano, S. Eaimkhong, D. Evseenko, J. Reed, A.Z. Stieg, J.K. Gimzewski, A. Nakano, Rigid microenvironments promote cardiac differentiation of mouse and human embryonic stem cells, Sci Technol Adv Mater, 14 (2013) 025003.

[84]. J. Zoldan, E.D. Karagiannis, C.Y. Lee, D.G. Anderson, R. Langer, S. Levenberg, The influence of scaffold elasticity on germ layer specification of human embryonic stem cells, Biomaterials, 32 (2011) 9612-9621.

[85]. H.C. Liang, Y. Chang, C.K. Hsu, M.H. Lee, H.W. Sung, Effects of crosslinking degree of an acellular biological tissue on its tissue regeneration pattern, Biomaterials, 25 (2004) 3541-3552.

[86]. T. Jiang, X.J. Ren, J.L. Tang, H. Yin, K.J. Wang, C.L. Zhou, Preparation and characterization of genipin-crosslinked rat acellular spinal cord scaffolds, Mater Sci Eng C Mater Biol Appl, 33 (2013) 3514-3521 